\title{
Asosiasi Gastropoda dengan Lamun di Perairan Teluk Awur dan Pulau Panjang, Jepara
}

\author{
Aldi Rivaldy Maulana*, Widianingsihi, Ita Widowati \\ Departemen IImu Kelautan, Fakultas Perikanan dan IImu Kelautan, Universitas Diponegoro \\ JI. Prof. H. Soedarto S.H, Tembalang, Semarang, Jawa Tengah 50275 Indonesia \\ ${ }^{*}$ Corresponding author, e-mail : arivaldy25@gmail.com
}

\begin{abstract}
ABSTRAK : Gastropoda adalah salah satu biota yang dapat berasosiasi dengan lamun. Kondisi padang lamun pada kedua lokasi akan mempengaruhi tingkat kerapatan dan kelimpahan biota yang berada di perairan. Penelitian ini bertujuan untuk mengetahui tingkat kerapatan lamun yang berbeda dan kelimpahan gastropoda serta hubungan antara tingkat kerapatan lamun yang berbeda dengan kelimpahan gastropoda. Pelaksanaan penelitian ini dilakukan pada bulan Mei dan Agustus 2020 di Perairan Teluk Awur dan Pulau Panjang, Jepara. Metode yang digunakan dalam penelitian ini adalah studi kasus yang bersifat deskriptif berdasarkan 3 kerapatan yang berbeda, yaitu kerapatan jarang, sedang, dan padat. Hasil penelitian menunjukkan terdapat 4 jenis lamun di Perairan Teluk Awur dan 5 jenis lamun di Perairan Pulau Panjang, yaitu Enhalus acoroides, Thalassia hempricii, Cymodocea serrulata dan Cymodocea rotundata dan Halophila ovalis. Kelimpahan gastropoda di kerapatan lamun jarang, sedang, dan padat di Teluk Awur adalah 67,5 ind $/ \mathrm{m}^{2}, 97 \mathrm{ind} / \mathrm{m}^{2}$ dan 10,5 ind $/ \mathrm{m}^{2}$, sedangkan kelimpahan gastropoda di kerapatan lamun jarang, sedang, dan padat di Pulau Panjang adalah 96 ind $/ \mathrm{m}^{2}, 97,5 \mathrm{ind} / \mathrm{m}^{2}$ dan 336,5 ind $/ \mathrm{m}^{2}$. Berdasarkan hasil regeresi menunjukkan antara kelimpahan gastropoda dengan kerapatan lamun terdapat korelasi yang erat, sehingga semakin tinggi kerapatan lamun akan diikuti oleh tingginya kelimpahan gastropoda.
\end{abstract}

Kata Kunci: Lamun; Gastropoda; Teluk Awur; Pulau Panjang

\section{Gastropod Association with Seagrass in the waters of Teluk Awur and Panjang Island Jepara}

\begin{abstract}
Seagrass beds are one of the marine ecosystems located in coastal areas and have an important role in the waters. Gastropods are one of the biota associated with seagrass beds. The conditions of the seagrass beds in both locations will affect the density and abundance of biota in the waters. This study aims to determine the different levels of seagrass density and abundance of gastropods and the relationship between different seagrass density levels and the abundance of gastropods. This research was carried out in May and August 2020 in the waters of Teluk Awur and Panjang Island, Jepara. The method used in this research is a descriptive case study based on 3 different densities, namely rare, medium, and dense. The research steps taken were sampling, identification, data analysis and data evaluation. The results showed that there were 4 types of seagrass in Teluk Awur waters and 5 types of seagrass in Panjang Island waters, namely Enhalus acoroides, Thalassia hempricii, Cymodocea serrulata and Cymodocea rotundata and Halophila ovalis. The abundance of gastropods in the rare, medium, and dense seagrass density in Awur 67,5 ind $/ \mathrm{m}^{2}, 97 \mathrm{ind} / \mathrm{m}^{2}$ dan $10,5 \mathrm{ind} / \mathrm{m}^{2}$, while the abundance of gastropods in the rare, medium and dense seagrass density in Panjang Island was $96 \mathrm{ind} / \mathrm{m}^{2}, 97,5 \mathrm{ind} / \mathrm{m}^{2}$ dan $336,5 \mathrm{ind} / \mathrm{m}^{2}$. Based on the regression results, there is a strong correlation between gastropod abundance and seagrass density, so that the higher the seagrass density will be followed by the higher gastropod abundance.
\end{abstract}

Keywords: Seagrass; Gastropods; Teluk Awur; Panjang Island

\section{PENDAHULUAN}

Perairan Teluk Awur dan Pulau Panjang merupakan perairan yang memiliki ekosistem lamun yang cukup luas. Yusniati (2015) menyatakan bahwa lamun merupakan satu-satunya tumbuhan berbunga yang menyesuaikan diri hidup terbenam dalam air laut dan lamun memiliki akar, daun, 
dan batang sejati. Ekosistem padang lamun merupakan salah satu dari 3 ekosistem penting di perairan yang pada umumnya terdapat di daerah tropis dan memilki peranan yang penting bagi biota invertebrata. Padang lamun memiliki fungsi sebagai daerah pemijahan, mencari makan, dan tempat berlindung bagi biota laut. Habitat padang lamun berada di perairan dangkal berpasir dan sering dijumpai di terumbu karang.

Biota laut yang berasosiasi dengan padang lamun salah satunya adalah hewan makrozoobenthos. Hewan makrozoobenthos yang umumnya banyak dijumpai pada habitat padang lamun salah satunya adalah hewan gastropoda. Gastropoda merupakan Mollusca yang bercangkang dan berjalan menggunakan perut, maka dari itu hewan ini memiliki alat gerak perut sebagai pengganti kaki untuk berjalan dan berpindah tempat (Harminto, 2003). Dalam rantai makanan gastropoda merupakan komponen yang memanfaatkan biomassa epifit pada lamun dan serasah pada di permukaan sedimen. Kehadiran gastropoda sangat dipengaruhi oleh adanya vegetasi lamun yang ada di daerah pesisir (Hitalessy et al., 2015). Gastropoda juga dapat digunakan sebagai salah satu indikator untuk mengetahui kondisi status lingkungan perairan. Penelitian ini bertujuan untuk mengetahui asosiasi gastropoda dan kerapatan pada padang lamun di Teluk Awur dan Pulau Panjang.

\section{MATERI DAN METODE}

Penelitian ini dilakukan pada bulan Mei dan Agustus 2020 di Perairan Teluk Awur dan Pulau Panjang, Jepara (Gambar 1). Metode pendataan lamun dan sampling gastropoda menggunakan metode purposive sampling yang mengacu pada metode dari buku Panduan Monitoring Pendataan Lamun LIPI (Rahmawati et al., 2017). Penentuan lokasi stasiun dengan menarik tiga transek paralel dengan jarak $50 \mathrm{~m}$ antar transek dan tegak lurus dengan garis pantai. Identifikasi lamun dilakukan setiap $10 \mathrm{~m}$ dengan transek kuadran persegi yang berukuran $50 \mathrm{~cm} \times 50 \mathrm{~cm}$ dimulai dari $0 \mathrm{~m}$ ditemukannya jenis lamun pertama hingga $100 \mathrm{~m}$ ke arah laut dengan total 11 kuadaran.

Sampling gastropoda menggunakan metode English (1994), pengambilan sampel gastropoda dilakukan dengan membentang transek panjang masing-masing $100 \mathrm{~m}$ ke arah laut dan jarak antara satu transek dengan yang lain adalah $50 \mathrm{~m}-100 \mathrm{~m}$. Pengambilan data sampel pada tiap transek menggunakan transek kuadrat $50 \times 50 \mathrm{~cm}$. Identifikasi gastropoda dilakukan di laboratorium dengan mengacu pada buku identifikasi gastropoda (Dharma, 2005).

Asosiasi antara gastropoda dengan lamun dapat dilihat dari kelimpahan gastropoda dan kerapatan lamun menggunakan analisa regresi linier. Variabel terikat adalah gastropoda dan variable bebas adalah kerapatan lamun. Menurut Sugiyono (2007), pedoman untuk memberikan interpretasi kooefisien korelasi adalah sebagai berikut: $0,00-0,199=$ Korelasi sangat lemah; 0,20 $-0,39=$ Korelasi lemah; $0,40-0,69=$ Tingkat korelasi sedang; $0,70-0,89=$ Tingkat korelasi kuat; $0,90-1,00=$ Tingkat korelasi sangat kuat.
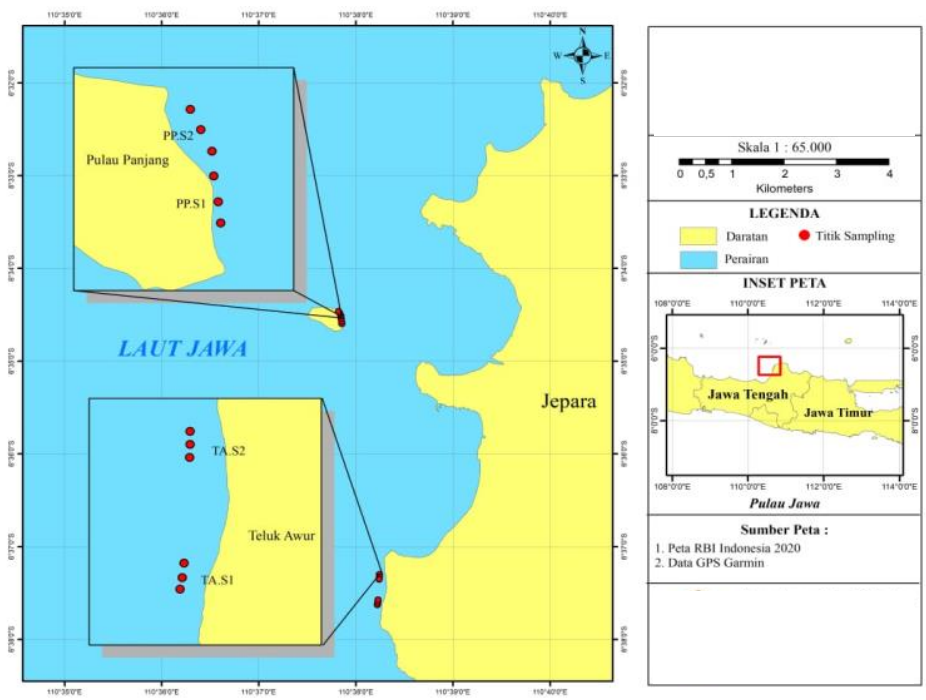

Gambar 1. Lokasi Penelitian Perairan Teluk Awur dan Pulau Panjang 


\section{HASIL DAN PEMBAHASAN}

Kerapatan lamun rapat, sedang, dan jarang di perairan Teluk Awur jenis lamun T. hempricii merupakan jenis yang berjumlah paling banyak yaitu $277 \mathrm{ind} / \mathrm{m}^{2}, 757 \mathrm{ind} / \mathrm{m}^{2}, 228 \mathrm{ind} / \mathrm{m}^{2}$. Sedangkan jenis $C$. rotundata merupakan jenis lamun yang paling sedikit kerapatannya, yaitu $5 \mathrm{ind} / \mathrm{m}^{2}, 15$ ind $/ \mathrm{m}^{2}, 0$ ind $/ \mathrm{m}^{2}$. Kerapatan dan komposisi lamun di perairan Teluk Awur tersaji pada Tabel 1.

Kerapatan lamun rapat, sedang, dan jarang di perairan Pulau Panjang jenis lamun T. hempricii merupakan jenis yang berjumlah paling banyak yaitu $1532 \mathrm{ind} / \mathrm{m}^{2}, 320 \mathrm{ind} / \mathrm{m}^{2}, 40 \mathrm{ind} / \mathrm{m}^{2}$. Sedangkan jenis $H$. ovalis merupakan jenis lamun yang paling sedikit kerapatannya, yaitu $5 \mathrm{ind} / \mathrm{m}^{2}, 15 \mathrm{ind} / \mathrm{m}^{2}, 0$ ind $/ \mathrm{m}^{2}$. Kerapatan dan komposisi lamun di perairan Teluk Awur tersaji pada Tabel 2.

Jenis lamun yang ditemukan di perairan Teluk Awur terdapat 4 spesies, yaitu Enhalus acoroides, Thalassia hempricii, Cymodocea serrulata, dan Cymodocea rotundata. Sedangkan pada perairan Pulau Panjang ditemukan 5 spesies lamun, yaitu yaitu Enhalus acoroides, Thalassia hempricii, Cymodocea serrulata, Cymodocea rotundata, dan Halophila ovalis. Jenis lamun Thalassia hempricii merupakan lamun yang paling banyak ditemukan di perairan Teluk Awur dan Pulau Panjang karena sifatnya yang memiliki kemampuan adaptasi yang berbeda dengan lamun jenis lainnya. Adaptasi tersebut dapat dilihat dari bentuk daun yang lebar dan tebal serta adanya rhizome yang membuat sistem perakaran yang kuat (Setyawati et al., 2014). Kesesuaian dengan substrat di kedua lokasi juga mempengaruhi banyaknya jenis lamun $T$. hempricii dan ditemukan substrat pada lokasi penelitian yaitu substrat pasir (sand), yang cocok dengan jenis lamun ini. Dahuri (2003), menyatakan jenis lamun $T$. hempricii termasuk spesies yang jumlahnya bisa berlimpah serta memiliki penyebaran yang luas.

Tabel 1. Kerapatan dan komposisi lamun di perairan Teluk Awur

\begin{tabular}{clcccccc}
\hline & & \multicolumn{2}{c}{ Lamun Rapat } & \multicolumn{2}{c}{ Lamun Sedang } & \multicolumn{2}{c}{ Lamun Jarang } \\
No. & \multirow{2}{*}{ Jenis Lamun } & $\mathrm{ni}$ & $\mathrm{KR}$ & $\mathrm{ni}$ & $\mathrm{KR}$ & $\mathrm{ni}$ & $\mathrm{KR}$ \\
& & $\mathrm{ind} / \mathrm{m}^{2}$ & $(\%)$ & $\mathrm{ind} / \mathrm{m}^{2}$ & $(\%)$ & $\mathrm{ind} / \mathrm{m}^{2}$ & $(\%)$ \\
\hline 1 & Enhalus acoroides & 4 & 1.31 & 22 & 2.64 & 12 & 4.88 \\
2 & Thalassia hempricii & 277 & 90.52 & 757 & 90.77 & 228 & 92.68 \\
3 & Cymodocea serrulata & 20 & 6.54 & 40 & 4.80 & 6 & 2.44 \\
4 & Cymodocea rotundata & 5 & 1.63 & 15 & 1.80 & 0 & 0.00 \\
\hline & Jumlah (Ind/m ${ }^{2}$ ) & 306 & 100 & 834 & 100 & 246 & 100 \\
\hline
\end{tabular}

Tabel 2. Kerapatan dan komposisi lamun di perairan Pulau Panjang

\begin{tabular}{cccccccc}
\hline \multirow{2}{*}{ No. } & \multirow{2}{*}{ Jenis Lamun } & \multicolumn{2}{c}{ Lamun Rapat } & \multicolumn{2}{c}{ Lamun Sedang } & \multicolumn{2}{c}{ Lamun Jarang } \\
\cline { 3 - 8 } & & $\mathrm{ni}$ & $\mathrm{KR}$ & $\mathrm{ni}$ & $\mathrm{KR}$ & $\mathrm{ni}$ & $\mathrm{KR}$ \\
& & $\mathrm{ind} / \mathrm{m}^{2}$ & $(\%)$ & $\mathrm{ind} / \mathrm{m}^{2}$ & $(\%)$ & $\mathrm{ind} / \mathrm{m}^{2}$ & $(\%)$ \\
\hline 1 & Enhalus acoroides & 77 & 2.20 & 9 & 1.45 & 10 & 6.41 \\
2 & Thalassia hempricii & 1532 & 43.68 & 320 & 51.61 & 40 & 25.64 \\
3 & Cymodocea serrulata & 716 & 20.42 & 107 & 17.26 & 78 & 50.00 \\
4 & Cymodocea rotundata & 1106 & 31.54 & 174 & 28.06 & 28 & 17.95 \\
5 & Halophila ovalis & 76 & 2.17 & 10 & 1.61 & 0 & 0.00 \\
\hline & Jumlah $\left(\right.$ Ind $/ \mathrm{m}^{2}$ ) & 3507 & 100 & 620 & 100 & 156 & 100 \\
\hline
\end{tabular}

Keterangan ni : jumlah individu; KR : Kerapatan 
Jenis lamun yang paling sedikit ditemukan di perairan Teluk Awur dan Pulau Panjang adalah spesies lamun Halophila ovalis. $H$. ovalis memiliki ukuran lamun yang cukup kecil dan hanya ditemukan hidup di daerah substrat yang berpasir, dan memiliki akar rambut yang berdiameter kecil dan rapuh. Lamun $H$. ovalis dapat hidup diantara jenis lainnya karena lamun jenis ini rentan terhadap arus yang kuat tetapi dapat hidup di daerah keadaan minim dari paparan sinar matahari (Setyawati et al., 2014). Menurut BTNKJ (2007) H. ovalis hidup di daerah intertidal yang tidak terpapar oleh sinar matahari secara langsung dan hidup pada keadaan sedimen yang butirannya halus hingga pasir dengan pecahan karang. Perbedaan jenis lamun yang ditemukan di perairan Teluk Awur dan Pulau Panjang dapat dipengaruhi oleh perbedaan kondisi perairan dan lingkungannya seperti, kedalaman, perbedaan substrat dasar perairan, kecerahan, dan lain lain. Pengaruh dari pasang surut air laut yang rendah juga dapat menyebabkan kerusakan pada lamun terutama di daerah perairan yang dangkal.

Komposisi gastropoda yang di temukan di perairan Teluk Awur dan Pulau Panjang terdiri dari 10 jenis gastropoda yang berasosiasi di ekosistem padang lamun. Kelimpahan gastropoda dengan kerapatan yang berbeda yaitu rapat, sedang dan jarang paling banyak ditemukan di perairan Teluk Awur dan Pulau Panjang adalah jenis Cerithium tjilonganense sebanyak $156 \mathrm{ind} / \mathrm{m}^{2}$ di Teluk Awur dan $143 \mathrm{ind} / \mathrm{m}^{2}$ di perairan Pulau Panjang sedangkan spesies yang paling sedikit ditemukan adalah jenis $C$. eglatina. Kelimpahan dan komposisi gastropoda di Perairan Teluk Awur dan Pulau Panjang tersaji pada Tabel 3.

Gastropoda yang ditemukan di perairan Teluk Awur terdapat 4 spesies, yaitu Cerithium tjilonganense, Cantharus fumosus, Astralium semicostafum, dan Vexilium rugosum. Sedangkan pada perairan Pulau Panjang ditemukan 10 spesies, yaitu Tectus fenestratus, Trochus maculatus, Astralium semicostafum, Vexilium rugosum, Xenophora solaris, Nassarius castus, Turbo intercostalis, Cerithium tjilonganense, Cantharus fumosus, dan Cypraea eglatina. Dari kedua lokasi didapatkan spesies gastropoda yang paling banyak ditemukan adalah spesies $C$. tjilonganense, sedangkan yang sedikit ditemukan adalah spesies $C$. eglatina. Tingginya nilai kepadatan $C$. tjilonganense diduga karena jenis ini memiliki sebaran yang luas, karena hampir ditiap plot pengambilan gastropoda ditemukannya spesies tersebut. Jenis gastropoda $C$. tjilonganense yang termasuk dalam famili cerithiidae memiliki penyebaran yang luas dan beragam, mulai dari daerah berlumpur, berpasir, serta pantai berbatu. Hal ini juga didukung oleh penelitian Syaffitri (2003), bahwa jenis gastropoda pada kelas Cerithiidae merupakan jenis yang paling banyak dijumpai serta jenis yang memiliki penyebaran paling luas di ekosistem perairan. Jenis ini adalah kelompok asli penghuni ekosistem perairan laut dan memiliki kehidupan pada substrat pasir hingga lumpur serta memilki kelimpahan yang cukup tinggi.

Tabel 3. Kelimpahan (Ind/ $/ \mathrm{m}^{2}$ ) dan komposisi gastropoda di Teluk Awur dan Pulau Panjang

\begin{tabular}{lcccccc}
\hline \multirow{2}{*}{ Spesies Gastropoda } & \multicolumn{3}{c}{ Teluk Awur } & \multicolumn{3}{c}{ Pulau Panjang } \\
\cline { 2 - 7 } & Rapat & Sedang & Jarang & Rapat & Sedang & Jarang \\
\hline Tectus fenestratus & - & - & - & 49,5 & 17 & 12 \\
Trochus maculatus & - & - & - & 46,5 & 8 & 5,5 \\
Astralium semicostafum & - & 0,5 & - & 19 & 0,5 & - \\
Vexilium rugosum & - & - & 0,5 & 4,5 & - & - \\
Xenophora solaris & - & - & - & 11,5 & 0,5 & - \\
Nassarius castus & - & - & - & 15,5 & 0,5 & - \\
Turbo intercostalis & - & - & - & 77 & 26 & 21,5 \\
Cerithium tjilonganense & 9,5 & 86 & 60,5 & 71,5 & 26,5 & 45 \\
Cantharus fumosus & 1 & 10,5 & 6,5 & 41 & 18,5 & 12 \\
Cypraea eglatina & - & - & - & 0,5 & - & - \\
\hline Jumlah & 10,5 & 97 & 67,5 & 336,5 & 97,5 & 96 \\
\hline
\end{tabular}


Kesesuaiannya lingkungan sangat berpengaruh dengan kelimpahan dari gastropoda maupun hewan epifauna lainnya. Kerapatan lamun yang tinggi memungkinkan gastropoda dan hewan epifauna lainnya mendapatkan tempat perlindungan dan menyediakan sumber makanan dari serasah lamun. Menurut Derbali et al. (2012), keberadaan spesies gastropoda juga dipengaruhi oleh pergerakannya pada saat pasang naik yang merupakan penghindaran dari pemangsaan. Pengaruh dari tidak banyaknya predator dari $C$. tjilonganense sendiri juga bisa dijadikan faktor berlimpahnya spesies ini pada kedua lokasi penelitian. Faktor lainnya juga dapat didukung oleh substrat pada kedua lokasi yaitu, pasir (sand). Hal ini sesuai dengan Menurut Nybakken (2000), dimana tipe substrat yang berpasir memudahkan mollusca untuk mendapatkan suplai nutrient dan air yang diperlukan untuk kelangsungan hidupnya. Tipe substart berpasir juga akan memudahkan menyaring makanan yang diperlukan dibandingkan dengan tipe substrat yang berlumpur. Substrat dasar pada kedua lokasi penelitian keseluruhan memiliki tipe substrat pasir (sand). Substrat ini cocok untuk kehidupan makrozobenthos karena umumnya substrat pasir maupun pasir campuran mengandung banyak bahan organik yang dapat dimanfaatkan sebagai bahan makanan oleh hewan makrozoobenthos (Sari et al., 2019).

Asosiasi dari hubungan antara kelimpahan gastropoda dengan kerapatan lamun yang berbeda di perairan Teluk Awur dan Pulau Panjang disajikan pada Gambar 2. Hubungan gastropoda dengan kerapatan lamun berdasarkan nilai dari koefisien $r$ sebesar 0,990 menunjukkan bahwa kerapatan lamun mempunyai pengaruh yang kuat terhadap kelimpahan gastropoda di perairan Teluk Awur, sedangkan nilai koefisien $r$ di perairan Pulau Panjang yaitum, 0,839 menunjukkan bahwa kerapatan lamun mempunyai pengaruh yang kuat terhadap kelimpahan gastropoda. Hasil analisis regresi linier sederhana asosiasi gastropoda dengan kerapatan lamun di perairan Teluk Awur memiliki nilai koefisien determinasi $\left(R^{2}\right)$ sebesar, 0,7051 menunjukkan $70,51 \%$ kelimpahan gastropoda dipengaruhi oleh kerapatan lamun dan $29.49 \%$ kelimpahan gastropoda dipengaruhi oleh faktor lain. Nilai korelasi asosiasi gastropoda dengan kerapatan lamun di perairan Pulau Panjang memiliki koefisien determinasi $\left(R^{2}\right)$ sebesar, 0,9805 menunjukkan 98,05\% kelimpahan gastropoda dipengaruhi oleh kerapatan lamun dan $1.95 \%$ dipengaruhi oleh faktor lain. Perairan Teluk Awur memilki persamaan regresi linier $Y=0,1071 x+1,6459$ nilai positif pada grafik menunjukkan hubungan searah yaitu, semakin tinggi nilai kerapatan lamun maka semakin tinggi kelimpahan gastropoda. Perairan Pulau Panjang memilki persamaan regresi linier $Y=0,06 x+15,731$ nilai positif pada grafik menujukkan hubungan searah yang positif, semakin tinggi nilai kerapatan lamun maka semakin tinggi kelimpahan gastropoda. Kerapatan lamun yang tinggi tentunya sesuai dengan pernyataan Prasetya et al. (2015), mengatakan hubungan antara kelimpahan hewan makarozoobenthos dengan kerapatan lamun yang berbeda bernilai positif memiliki arti pada setiap peningkatan jumlah kerapatan lamun makan diikuti dengan peningkatan jumlah makrozoobenthos.

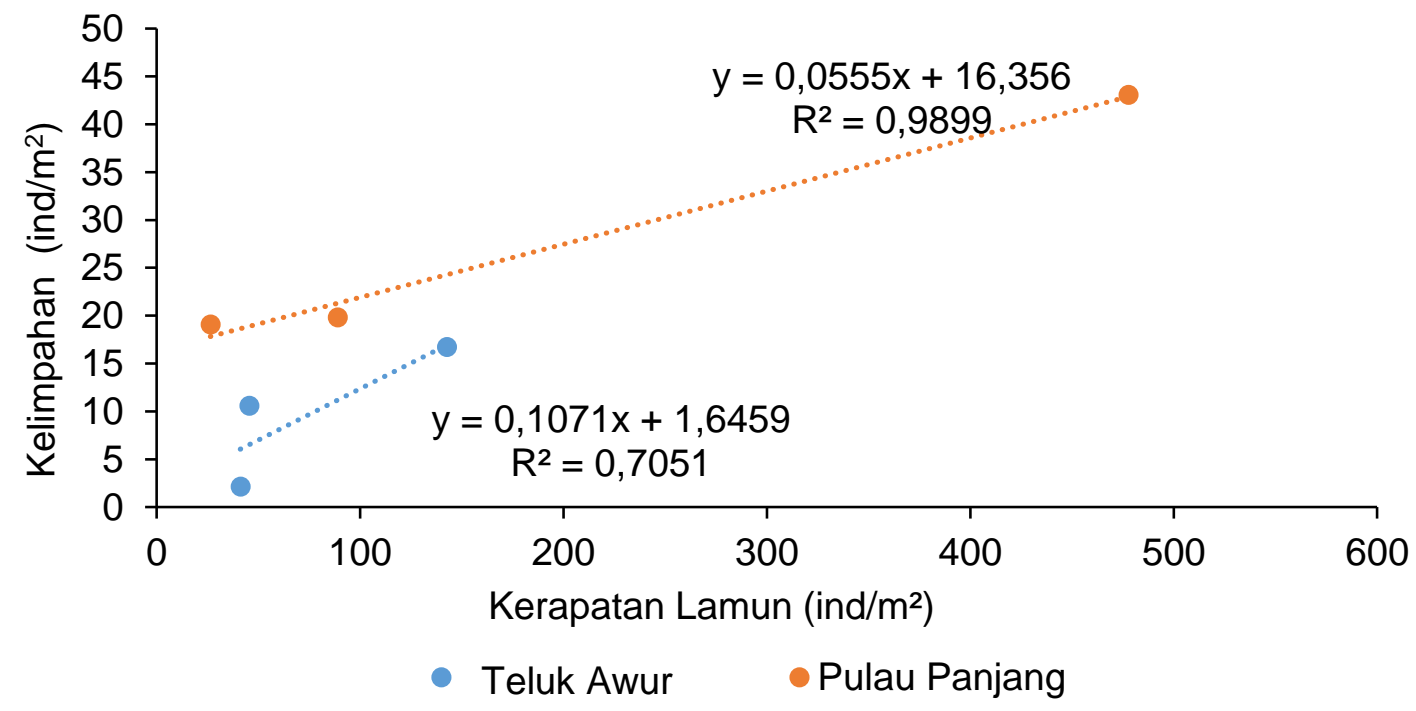

Gambar 2. Hubungan Kelimpahan Gastropoda dengan Kerapatan Lamun di Perairan Teluk Awur dan Pulau Panjang 


\section{KESIMPULAN}

Nilai korelasi kelimpahan gastropoda dengan kerapatan lamun di perairan Teluk Awur, yaitu 0,990 yang menunjukkan bahwa tingkat korelasi sangat kuat dan di Pulau Panjang yaitu, 0,839 yang menunjukkan hubungan yang kuat dan positif dari asosiasi gastropoda dengan kerapatan lamun pada kedua lokasi yang artinya setiap peningkatan jumlah kerapatan lamun maka akan diikuti dengan peningkatan hewan gastropoda.

\section{DAFTAR PUSTAKA}

BTNKJ. 2007. Monitoring Lamun di Taman Nasional Karimunjawa. Balai Taman Nasional Karimunjawa. Jepara.

Dahuri, R. 2003. Keanekaragaman Hayati, Laut dan Aset Pembangunan Berkelanjutan. PT Gramedia Pustaka Utama. Jakarta.

Derbali, A., Elhasni, K., Jarboui, O., \& Ghorbel, M. 2012. Distribution, Abundance, and Biological Parameters of Cerastoderma glaucum (Mollusca: Bivalvia) along the Gabes Coasts (Tunisia, Central Mediterranean). Acta Adriatica, 53: 363-374.

Dharma, B. 2005. Recent \& Fossil Indonesian Shells. Conchbooks, Hackenheim,Germany.

English, S., Wilkinson, C. \& Baker, V. 1994. Survey Manual for Tropical Marine Resources. Published on Behalf of the ASEAN-Australian Marine Science. Townsvile : $367 \mathrm{pp}$.

Harminto, S. 2003. Taksonomi Avertebarata. Jakarta: Universitas Terbuka. hlm 24-26.

Hitalessy, R.B., Leksono, A.S. \& Herawati, E.Y., 2015. Struktur Komunitas Dan Asosiasi Gastropoda Dengan Tumbuhan Lamun di Perairan Pesisir Lamongan Jawa Timur. Indonesian Journal of Environment and Sustainable Development, 6(1):64-73.

Nybakken, J.W. 2000. Biologi Laut; Suatu Pendekatan Ekologis. Terjemahandari Marine Biology and Ecology oleh Eidman, M. Koesoebiono. PT Gramedia, Jakarta Halaman???

Prasetya, D.K., Ruswahyuni, N. \& Widyorini. 2015. Hubungan Antara Kelimpahan Hewan Makrobenthos Dengan Kerapatn Lamun Yang Lamun Yang Berbeda Di Pulau Panjang dan Teluk Awur Jepara. Diponegoro Journal Of Maquares, 4(4): 155-163

Rahmawati, Irawan, S.A., Supriyadi, I.H. \& Azkab, M.H. 2017. Panduan Monitoring Padang Lamun. CRITC COREMAP CTI LIPI.

Sari, P.D., Ulqodry, T.Z., Aryawati, R. \& Isnaini, I.. 2019. Asosiasi Gastropoda dengan Lamun (Seagrass) di perairan Pulau Tangkil Lampung. Jurnal Penelitian Sains 21(3): 131-139. DOI: 10.36706/jps.v21i3.546

Setyawati, Y., Subiyanto, \& Ruswahyuni. 2014. Hubungan Antara Kelimpahan Epifauna Dasar Dengan Tingkatan Kerapatan Lamun yang Berbeda di Pulau Panjang dan Teluk Awur Jepara. Diponegoro Journal of Maquares, 3(4):235-242. DOI: 10.14710/marj.v3i1.4504

Sugiyono. 2007. Metode penelitian pendidikan, metode kuantitatif, kualitatif dan R\&D. Bandung: Alphabeta.

Syaffitri, E. 2003. Struktur Komunitas Gastropoda (Mollusca) di Hutan Mangrove Muara Sungai Donan Kawasan BKPH Rawa Timur, KPH Banyumas Cilacap, Jawa Tengah. Skripsi. Institut Pertanian Bogor.

Yusniati. 2015. Jenis-jenis lamun di Perairan Laguna Tasilaha dan pengembangannya sebagai media pembelajaran biologi. Jurnal Sains dan Teknologi Tadulako. 4(1):13-22 